\title{
Purificação de amilases de malte de Zea mays
}

\author{
Purification of amylases from Zea mays malt
}

\author{
Joana Paula Menezes BIAZUS ${ }^{1}$, José Carlos Curvelo SANTANA ${ }^{2,3}$, \\ Roberto Rodrigues de SOUZA ${ }^{1}$, Elias Basile TAMBOURGI ${ }^{2 *}$
}

\begin{abstract}
Resumo
Neste trabalho realizou-se a purificação das enzimas a e $\beta$-amilases de malte de milho combinando os processos de adsorção em leito expandido com o fracionamento por etanol. Alimentaram-se $5 \mathrm{~mL}$ de uma solução a $2 \%$ de malte de milho em tampão fosfato $0,05 \mathrm{M}$ a pH 5 em uma coluna contendo as resinas de troca iônica Amberlite IRA 410, em leito fixo de $4 \mathrm{~cm}$ fluidizado para $8 \mathrm{~cm}$. A eluição foi promovida com $\mathrm{NaCl} 0,25 \mathrm{M}$ com $14 \mathrm{~mL} /$ minuto de vazão descendente e o material eluído foi fracionado com álcool etílico nas concentrações de $40-70 \%, 50-80 \%$ e $60-90 \%$ (v/v) a 20 e $30{ }^{\circ} \mathrm{C}$. A recuperação da atividade e o fator de purificação foram de $95 \%$ e 23 vezes, respectivamente, na primeira etapa. A melhor condição de fracionamento das enzimas foi apresentada a $50-80 \%$ de álcool e $20{ }^{\circ} \mathrm{C}$, e o fator de purificação ficou acima de 100 vezes.
\end{abstract}

Palavras-chave: adsorção em leito expandido; precipitação; amilases; malte de milho; álcool etílico; resina de troca iônica.

\begin{abstract}
In the present work the purification of $\alpha$ and $\beta$-amylase enzymes of maize malt was carried out by expanded bed adsorption and ethanol fractionation downstream processes. $5 \mathrm{~mL}$ of $2 \%$ maize malt solution in $0.05 \mathrm{M}$ phosphate buffer at $\mathrm{pH}$ was injected into a chromatographic column containing Amberlite 410 ion-exchange resin, on a $4 \mathrm{~cm}$ fixed bed fluidized to $8 \mathrm{~cm} .0 .25 \mathrm{M} \mathrm{NaCl} \mathrm{solution}$ at $14 \mathrm{~mL} / \mathrm{minuto}$ of descending flux was used for promotion of the elution, the eluted matter was fractioned by 40-70, 50-80 and 60-90\% ethyl alcohol concentration at 20 and $30^{\circ} \mathrm{C}$. Activity recovery and purification factor were of $95 \%$ and 23 times, respectively, in the first step. 50-80\% alcohol concentration at $20^{\circ} \mathrm{C}$ was the best condition, in which a purification factor of more than 100 times was achieved.

Keywords: expanded bed adsorption; precipitation; amylases; corn malt; ethyl alcohol; ion-exchange resin.
\end{abstract}

\section{Introdução}

Tipicamente, o processo de purificação de uma proteína é composto por múltiplas etapas cuidadosamente definidas que têm como fundamento à distinção das proteínas com base na sequência de aminoácidos, no conteúdo de carboidratos e de lipídios na estrutura tridimensional, e na sua atividade biológica. Estes processos são mais conhecidos como processos de prépurificação. Nos últimos anos,,foi dada atenção considerável ao desenvolvimento das então chamadas operações integradas de processos, das quais os três passos mais clássicos são: separação sólido-líquido, concentração e isolamento primário de produtos, que são fundidas em uma só unidade de operação (ALMEIDA; KURTEMBACK, 2002; SANTOS, 2001).

Os processos semelhantes levam a uma redução do número de operações unitárias necessária ao processo de purificação e, desta maneira, prometem não só uma alta recuperação, mas também uma economia superior na obtenção destes produtos. Um método que se destaca nesta última classe de operações unitárias é de uso comum em unidades de bancada e chama-se adsorção em leito expandido (ALE) (ALMEIDA; KURTEMBACK, 2002; SANTOS, 2001).

A ALE proporciona a alimentação de material biológico diretamente do meio originário (bruto) pela coluna cromatográfica, já que seu leito é expandido, o que reduz os custos com outros processos de pré-purificação (DAINIAK et al., 2002; ROY et al., 1999; SANTOS, 2001; TOLEDO et al., 2007).

A precipitação é uma das operações mais adotadas para a purificação de proteínas tanto de origem microbiana como animal ou vegetal. É uma das principais técnicas utilizadas para a separação de proteínas de uma mistura em virtude da sua simplicidade e tem sido empregada há décadas. Tradicionalmente é considerada como um método de concentração e utilizada antes da aplicação de métodos de maior resolução na purificação (LUCCARINI; KILIKIAN; PESSOA Jr. 2005).

Uma das vantagens do uso de solventes é a volatilidade, que permite pronta recuperação e reciclagem ao processo, além de possuir propriedades bactericidas. Por outro lado, a principal

${ }^{1}$ Departamento de Engenharia Química, Universidade Federal de Sergipe - UFS, Cidade Universitária prof. "José Aloísio de Campos, Av. Marechal Rondon, S/N, Rosa Elze, CEP 49100-000, São Cristóvão - SE, Brasil

2 Departamento de Engenharia de Sistemas Químicos, Faculdade de Engenharia Química,Universidade de Campinas - UNICAMP, Cidade Universitária "Zeferino Vaz", Av. Albert Einstein, 500, Barão Geraldo, Campinas - SP, Brasil, CP 6066, CEP 13083-970, E-mail: eliastam@feq.unicamp.br.

${ }^{3}$ Departamento de Ciências Exatas, Universidade Nove de Julho - UNINOVE, Rua Vergueiro, 235/249, Liberdade, CEP 01504-001, São Paulo - SP, Brasil

${ }^{*}$ A quem a correspondência deve ser enviada 
desvantagem dos solventes é a tendência de causarem mudanças conformacionais nas biomoléculas e inflamabilidade, exigindo, por vezes, baixas temperaturas de operação para trabalhos em larga escala (LUCCARINI; KILIKIAN; PESSOA Jr. 2005).

Atualmente há uma grande utilização de solventes orgânicos, principalmente o metanol, o etanol e a acetona. $\mathrm{O}$ principal efeito da precipitação por solventes orgânicos é que o poder de solvatação nas regiões carregadas e hidrofílicas da superfície da proteína diminui com o aumento da concentração do solvente e aumenta as forças eletrostáticas de atração entre as moléculas de proteína. Na precipitação por solventes, algumas variáveis que afetam o mencionado processo devem ser levadas em consideração, dentre elas estão a temperatura e o pH (CARVALHO; GARCIA; WADA, 2005; LUCCARINI; KILIKIAN; PESSOA Jr., 2005).

As a-amilase (EC3.3.1.1; $\alpha$-1,4 glicano, 4-glicanohidroxilase) e $\beta$-amilase (EC 3.2.1.1, $\alpha$-1,4, glicanomaltohidrolase) são enzimas que hidrolisam ligações $\alpha-1,4$ não terminais de moléculas de amilose, amilopectina, glicogênio e dextrinas, gerando glicose, maltose, trioses e outras oses, porém não atuando sobre as ligações $\alpha-1,6$. Seus pHs ótimos estão entre 4,5 e 6,5 e suas temperaturas ótimas estão compreendidas entre 55 e $75^{\circ} \mathrm{C}$, enquanto que suas massas molares variam para a a-amilase de 50 a $120 \mathrm{kDa}$ e de 22 a $50 \mathrm{kDa}$ para a $\beta$-amilase, dependendo das suas origens (AGUILAR et al., 2000; BIAZUS et al., 2006a, 2007; BLASQUEZ et al., 1998; FURUYA et al., 1995, 1996; REGULY, 1996; WISEMAN, 1987).

As amilases podem ser obtidas de várias fontes: de alguns micro-organismos, de cereais e até de animais. Elas são usadas para hidrolisar o amido, sendo empregadas pelas indústrias alimentícias, têxteis, farmacológicas e principalmente nas de álcool durante a produção de cerveja sob a forma de malte de cevada (cereal este, não produzido no País), e seus preços, após purificação, podem alcançar US\$ 1500,00.g-1 (SIGMA, 1996).

O milho (Zea mays) é um produto agrícola muito difundido no Brasil, comercializado in natura, ou pouco processado e é vendido a baixo preço. A obtenção das enzimas $\alpha$ e $\beta$-amilases do seu malte gerariam um produto de alto valor agregado (BIAZUS et al., 2006a, 2007; FERREIRA et al., 2007; CURVELOSANTANA, 2003; SEVERO Jr. et al., 2007).

O presente trabalho teve como objetivo estudar a purificação de amilases de malte de milho (Zea mays), tendo, como etapas de pré-purificação, a adsorção em leito expandido (ALE) e, como de purificação, o fracionamento utilizando álcool etílico para gerar um produto com baixo custo de obtenção, de alto valor agregado e bom grau de pureza.

\section{Materiais e métodos}

\subsection{Materiais}

Reagentes: as sementes de milho comum foram adquiras junto à EMBRAPA (Tabuleiros Costeiro) sediada em AracajuSE. O ácido o-fosfórico PA foi adquirido junto à Synth (Diadema-SP, Brasil), o acetato de sódio PA, o ácido acético PA, o ácido dinitrosalicílico (DNS), o álcool etílico PA e o alginato de sódio foram adquiridos da VETEC (São Paulo, Brasil), enquanto que o azul brilhante de Comassie-G e o amido solúvel foram adquiridos da MERCK (Berlim, Alemanha).

Fluidizador: o tampão fosfato $0,05 \mathrm{M}$ a pH 5 foi usado como promotor da fluidização do meio por não possuir o contra íon da resina aniônica $\left(\mathrm{Cl}^{-}\right)$e por ser este $\mathrm{pH}$ o citado como próximo do ótimo das enzimas (BIAZUS et al., 2006b, 2007; REGULY, 1996; WISEMAN, 1987). Suas propriedades físicas estão apresentadas na Tabela 1 , medidas por viscosimetria e densimetria. As propriedades da água foram encontradas na literatura (STREETER, 1977).

Coluna de adsorção em leito expandido (ALE): Foi usada uma coluna de vidro com dimensões de $1 \times 30 \mathrm{~cm}$, contendo um pistão de altura ajustável na parte superior e uma tela de mesh 60 entre as junções inferiores da coluna e na parte inferior do pistão para evitar perda de adsorventes. Uma régua foi usada na lateral da coluna para o ajuste da altura do leito, com alimentações do tampão de fluidização e do sal na eluição fornecidas por bombas peristálticas (Figura 1).

Obtenção do malte de milho: as sementes foram selecionadas, pesadas, lavadas, postas à absorção de umidade entre 40\% e 45\% e colocadas em meio germinativo em escala laboratorial por aproximadamente 4 a 5 dias. $\mathrm{O}$ meio germinativo foi composto de uma camada de $1 \mathrm{~cm}$ de algodão sobreposta por folhas de papel de filtro A4, sobre as quais as sementes úmidas foram postas para germinar. A cada duas horas, as sementes eram molhadas para não reduzir o seu teor de umidade, até o quinto dia, quando foram retiradas do meio germinativo e retiradas as suas raízes e talos. Depois, o malte foi seco a $55^{\circ} \mathrm{C}$, triturado, armazenado

Tabela 1. Propriedades físicas dos fluidos a $22^{\circ} \mathrm{C}$.

\begin{tabular}{ccc}
\hline Propriedades & \multicolumn{2}{c}{ Fluidos } \\
\cline { 2 - 3 } & Água & Tampão Fosfato \\
\hline$\rho_{\mathrm{L}}\left(\mathrm{kg} / \mathrm{m}^{3}\right)$ & 997.5 & 1011 \\
$\mu(\mathrm{kg} / \mathrm{s} . \mathrm{m})$ & $9.384 \times 10^{-4}$ & $9.870 \times 10^{-4}$ \\
\hline
\end{tabular}

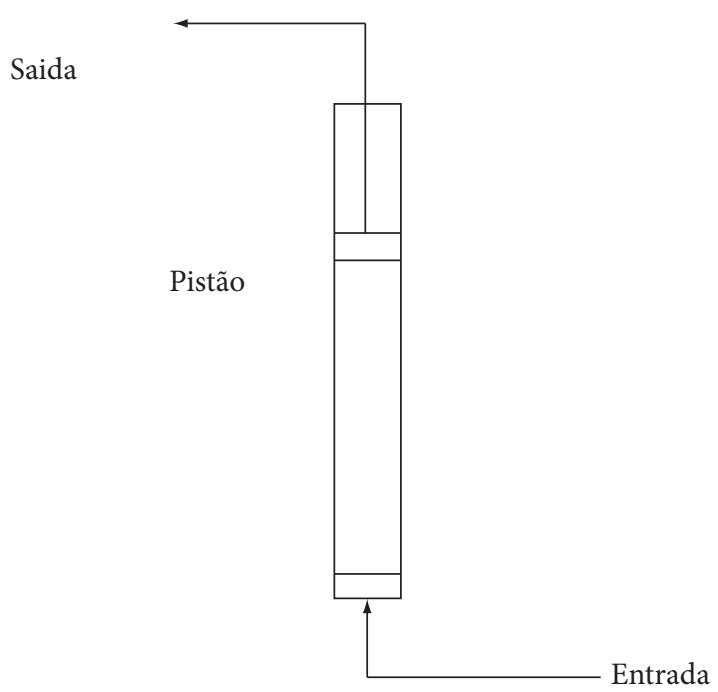

Figura 1. Esquema da coluna de ALE usada. 
e guardado a $5{ }^{\circ} \mathrm{C}$ (BIAZUS et al., 2005a, 2005b, 2006a, 2006b, 2006c, 2007; CURVELO-SANTANA, 2003; FERREIRA et al., 2007; SEVERO Jr. et al., 2007; TOLEDO et al., 2007).

Partículas adsorventes: a resina de troca aniônica, Amberlite IRA 410 com um diâmetro de partícula $\left(d_{\mathrm{p}}\right)$ de $4.4 \times 10^{-4} \mathrm{~m}$, massa específica $\left(\rho_{\mathrm{p}}\right)$ igual a $1120 \mathrm{~kg} \cdot \mathrm{m}^{-3}$ e capacidade de troca de cloreto igual a $1,3 \mathrm{meq} \mathrm{Cl}^{-} . \mathrm{mL}^{-1}$ de resina $\left(41,15 \mathrm{~g} \mathrm{Cl}^{-} . \mathrm{g}^{-1}\right.$ resina) foi utilizada como adsorvente nos experimentos (SIGMA, 1996).

\subsection{Métodos}

- Ensaios enzimáticos:

A $20 \mathrm{~mL}$ de uma solução de amido solúvel a 2\% em tampão acetato $0,1 \mathrm{M}$ a pH 4,8 foram adicionados $500 \mu \mathrm{L}$ de amostra enzimática, e a concentração de glicose gerada foi medida após 10 minutos de incubação a $30 \pm 2{ }^{\circ} \mathrm{C}$ pelo método do DNS. Uma unidade de atividade enzimática é dada como sendo a quantidade de glicose gerada em $\mu$ mol por 1 minuto sob as condições do ensaio (AGUILAR et al., 2000; BIAZUS et al., 2007; NIRMALA; MURALIKRISHNA, 2003; REGULY, 1996). A atividade específica é dada pela atividade por mg de proteína. A concentração de proteína foi medida pelo método de BRADFORD (1976).

- Purificação das amilases:

Adsorção em leito expandido: a adsorção das enzimas foi realizada com o sistema em leito expandido de 4 para $8 \mathrm{~cm}$ de altura, à temperatura e pressão ambientes $\left(22^{\circ} \mathrm{C}\right.$ e $1 \mathrm{~atm}$ ) e pH 5. O leito de adsorventes foi pré-equilibrado na altura de trabalho $(8 \mathrm{~cm})$ com o tampão fosfato numa velocidade de $18 \mathrm{~cm} /$ minuto em fluxo ascendente. Então, $5 \mathrm{~mL}$ da solução de malte de milho a $2 \%$ no tampão usado foram injetados abaixo do leito da coluna para promover a adsorção das enzimas sobre a resina Amberlite IRA 410. A eluição foi feita pelo uso de uma solução de $\mathrm{NaCl} 0,25 \mathrm{M} \mathrm{a}$ $14 \mathrm{~mL} /$ minuto de fluxo descendente (BIAZUS et al., 2006a; KALIL, 2000; SANTOS, 2001; TOLEDO et al., 2007). Amostras de $5 \mathrm{~mL}$ foram coletadas em tubos de ensaios nas saídas da coluna. A concentração de proteína total e a atividade enzimática foram medidas nestas amostras.

Fracionamento das proteínas: O material eluído foi fracionado com álcool etílico e os efeitos da concentração de etanol a $40-70 \%, 50-80 \%$ e $60-90 \%(v / v)$ e da temperatura a 20 e $30{ }^{\circ} \mathrm{C}$ foram verificados. $\mathrm{O}$ volume do extrato enzimático com o solvente não ultrapassou aos $10 \mathrm{~mL}$. Depois, estes foram colocados em tubos e após 24 horas (para as duas etapas da precipitação) os precipitados foram centrifugados a $6000 \mathrm{rpm}$, por 20 minutos e $4^{\circ} \mathrm{C}$. Determinou-se a quantidade de proteína total e atividade enzimática, tanto no precipitado quanto no sobrenadante, entretanto, apenas o segundo foi utilizado para efeito de cálculo, já que não se observou a purificação das enzimas na fase sólida (CARVALHO; GARCIA; WADA, 2005; LUCCARINI; KILIKIAN; PESSOA Jr.,2005).

Eletroforese desnaturante em gel de poliacrilamida (SDSPAGE): a eletroforese via SDS-PAGE foi desenvolvida em uma minicélula PROTEAN II (Bio-Rad, USA), com gel formado a partir de uma solução contendo $12 \%$ de gel de acrilamida, usando como marcadores de massa molar os padrões de proteína do kit da Bio-Rad. As proteínas das amostras brutas de malte de milho e do purificado por precipitação passaram por uma ultrafiltração com membrana de $10 \mu \mathrm{m}$ de diâmetro de poros, para eliminação da interferência salina e, depois, foram separadas sobre uma camada homogênea $0,8 \mathrm{~mm}$ do gel de resolução formado com acrilamida a $12 \%(\mathrm{p} / \mathrm{v})$ e do gel de separação formado com acrilamida a 4,8\% (p/v) com o sistema tampão usado por LAEMMLI (1970), em uma célula do tipo Bio-Rad Protean II. As proteínas separadas foram visualizadas após fixação com azul brilhante de coomassie G-250 (solução de fixação: ácido fosfórico $10 \%(\mathrm{v} / \mathrm{v})$ e coomassie $0,02 \%(\mathrm{p} / \mathrm{v})$ ) (AGUILAR et al., 2000; NIRMALA; MURALIKRISHNA, 2003; TOLEDO et al., 2007).

Rendimento da purificação: a eficiência dos processos foi avaliada por dois parâmetros, dados pelas Equações 1 e 2. A primeira é a recuperação da atividade enzimática $(R A)$ que compara a atividade total no material purificado com a atividade total no material bruto (dado em porcentagem) e a segunda é o fator de purificação $(F P)$ que compara a atividade enzimática específica total no material purificado com a atividade enzimática específica total no material bruto (BIAZUS et al., 2006a, 2007; SANTOS, 2001; TOLEDO et al., 2007), como Equações 1 e 2:

$$
\begin{aligned}
& R A=\frac{\text { AtividadeEnzimática } \operatorname{Re} \text { cuperada }}{\text { AtividadeEnzimáticaInicial }} * 100 \\
& F P=\frac{\text { AtividadeEnzimáticaEspecífica } \text { Re } \text { cuperada }}{\text { AtividadeEnzimáticaEspecíficaInicial }}
\end{aligned}
$$

\section{Resultados e discussão}

\subsection{Adsorção em leito expandido}

Nas Figuras 2, 3 e 4 estão apresentadas as curvas cromatográficas de proteínas, atividade e atividade específica, respectivamente, obtidas durante a adsorção em leito expandido (ALE). A adsorção de proteínas totais ocorreu por 1,5 minutos, enquanto que a adsorção de enzima oscilou até o quinto minuto, quando a resina foi saturada. Nos primeiros minutos de processo (adsorção), há um baixo registro tanto da concentração de proteína quanto da atividade enzimática, até que ocorre a saturação das resinas (as enzimas adsorveram na resina até o máximo possível) contidas na coluna e os valores destes parâmetros chegam aos seus máximos (o que leva à formação do pico), embora isso não ocorra ao mesmo tempo, o que demonstra uma maior afinidade da resina pelas enzimas, já que a adsorção dessas se prolonga por 5 minutos de processo. Ou seja, a lavagem da coluna com relação às proteínas totais ocorre antes da lavagem com relação às enzimas de interesse (pois estas continuam adsorvendo sobre as resinas). No malte de milho existem diversas proteínas, entretanto, apenas as enzimas amilases são de interesse. Depois, a resina é lavada e se percebe a redução da concentração de proteínas totais e da atividade enzimática. Na sequência, a eluição das enzimas é feita com o $\mathrm{NaCl}$ 0,25M, fazendo com que estas se desprendam das resinas (o que faz aparecerem os pequenos picos), sendo assim purificadas. 


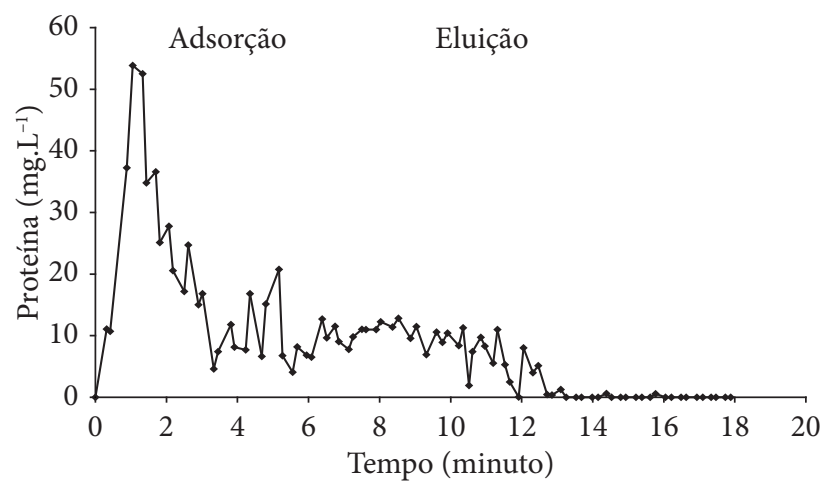

Figura 2. Curva cromatográfica das proteínas totais durante o processo de ALE.

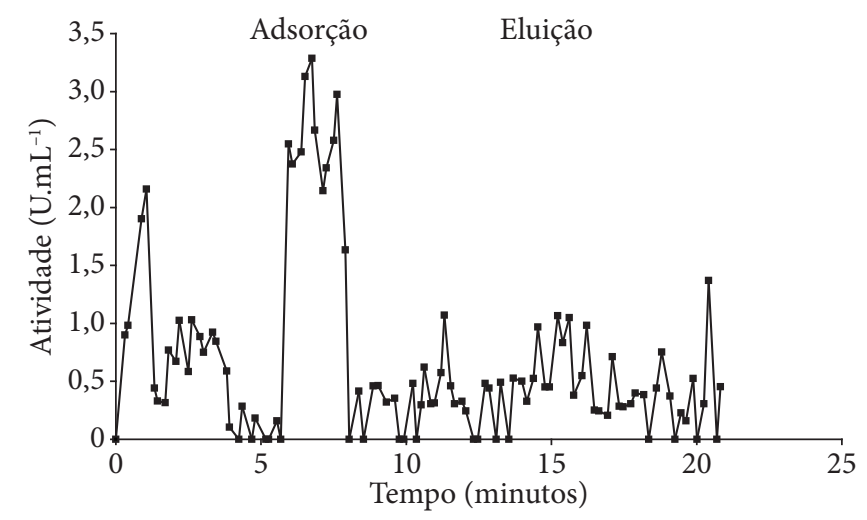

Figura 3. Variação da atividade durante o processo cromatográfico por ALE.

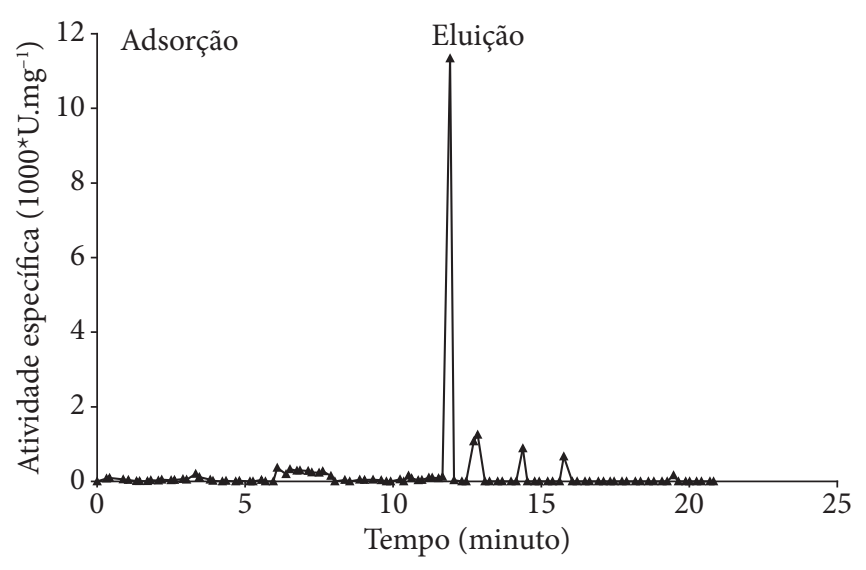

Figura 4. Comportamento da atividade por unidade (mg) de proteínas totais durante o processo cromatográfico por ALE.

A Figura 4 mostra que a resina praticamente reteve totalmente as enzimas $\alpha$ e $\beta$-amilases, pois ao se compararem as etapas de adsorção com a de eluição percebe-se que quase não houve passagem de material proteico com atividade durante a adsorção e lavagem da coluna, ao contrário do que é observado na eluição, na qual se veem picos cromatográficos das enzimas citadas e outras que também possuem atividades amilolíticas (como: amiloglucosidase, pectinase, etc.) (REGULY, 1996; WISEMAN, 1987).

Este fato comprova a boa afinidade existente entre a resina usada e as amilases. Isso provavelmente está ligado ao fato das amilases possuírem metais em sua estrutura, como cofatores $\left(\mathrm{Ca}^{2+}\right.$ para a $\alpha$-amilase e $\mathrm{Mg}^{2+}$ para a $\beta$-amilase), ou seja, estas enzimas são carregadas negativamente (FORGATY; KELLY, 1987; WISEMAN, 1987), e as resinas possuírem cátions derivados de amônio em suas estruturas, os quais possuem afinidade por ânions (KALIL, 2000; MENDU et al., 2005; SIGMA, 1996).

De acordo com Dainiak, Galaev e Matiasson (2002), Roy et al. (1999) e Santos (2001), a expansão do leito promove o aumento da área superficial exposta do adsorvente no meio fluidizado, o que promove uma maior interação partículapartícula e partícula-líquido, possibilitando uma maior transferência de massa da fase líquida para a sólida. Isso é uma das características mais importantes dos leitos fluidizados.

\subsection{Combinação de processos}

Na Tabela 2 estão apresentados os valores médios obtidos durante a recuperação de amilases de malte de milho, combinando-se a adsorção em leito expandido (ALE), como método primário, ao fracionamento de proteínas com etanol, como método secundário. Parte das proteínas das amostras obtidas durante a eluição (com alta concentração de $\mathrm{NaCl}$ ) foi precipitada com uma primeira adição de solvente. Para o fracionamento, usou-se o sobrenadante da primeira precipitação. Percebe-se que o índice de recuperação aumentou com a redução da temperatura e concentrações médias de etanol no fracionamento, o que corresponde às condições de precipitação em $50 \%$ de etanol e posterior fracionamento (com adição lenta do solvente) até $80 \%$ a $20^{\circ} \mathrm{C}$, a qual proporcionou a melhor resolução e um fator de purificação maior do que as 100 vezes. Este fator de purificação foi de 4,5 vezes maior do que o obtido durante o processo cromatográfico.

Segundo Luccarini, Kilikian e Pessoa Jr. (2005), a resolução do fracionamento é melhorada quando a concentração de proteína no meio é reduzida, percebe-se na Tabela 2 que o valor da proteína foi reduzido a cerca de $40 \%$ da proteína do malte inicial. Como as massas molares das amilases estão entre valores médios a altos, a resolução foi aumentada com a adição do solvente, até que se atingiu uma concentração em que as amilases começaram a precipitar e a sua purificação (no sobrenadante) foi reduzida. De acordo com Carvalho, Garcia e Wada (2005) e Luccarini, Kilikian e Pessoa Jr. (2005), à medida que se eleva a concentração do solvente e se reduz a temperatura do meio, as proteínas tendem a precipitar da menor para a maior massa molar.

A elevação da atividade recuperada acima do seu valor máximo contido no malte se dá devido à eliminação de agentes inibidores contidos no meio original (malte de milho), o que dá uma falsa presença de baixa atividade original no malte.

Estes inibidores são: os produtos originados pela hidrólise do amido de milho durante a germinação (glicose, maltose, dextrinas e demais oses), proteínas inibidoras geradas pelas 
Tabela 2. Resultados obtidos para a combinação dos processos de ALE com precipitação.

\begin{tabular}{|c|c|c|c|c|c|c|c|}
\hline & rocesso & Amostras & $\begin{array}{l}\text { Atividade } \\
\left(\mathrm{U}^{-\mathrm{L}^{-1}}\right)\end{array}$ & $\begin{array}{l}\text { Proteína } \\
\left(\mathrm{mg} . \mathrm{L}^{-1}\right)\end{array}$ & $\begin{array}{l}\text { At.Espec. } \\
\left(\mathrm{U} \mathrm{mg}^{-1}\right)\end{array}$ & $\begin{array}{l}\text { Atividade } \\
\text { Recuperada }\end{array}$ & $\begin{array}{c}\text { Fator de } \\
\text { Recuperação }\end{array}$ \\
\hline \multirow{6}{*}{ 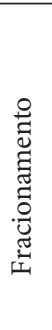 } & \multirow[t]{2}{*}{ ALE } & Malte bruto & 878,5 & 127,00 & 6,9168 & 100,00 & 1,0000 \\
\hline & & Eluido & 850,7 & 53,502 & 159,00 & 96,838 & 22,987 \\
\hline & \multirow{3}{*}{$20{ }^{\circ} \mathrm{C}$} & $40-70$ & 224,5 & 3,7464 & 59,934 & 42,500 & 8,6650 \\
\hline & & $50-80$ & 1169,8 & 1,6328 & 716,39 & 266,32 & 103,57 \\
\hline & & $60-90$ & 832,2 & 9,3647 & 88,863 & 236,82 & 12,847 \\
\hline & $30^{\circ} \mathrm{C}$ & $60-90$ & 0,0000 & 2,5749 & 0,0000 & 0,0000 & 0,0000 \\
\hline
\end{tabular}

sementes durante a fase de germinação que fazem reduzir e controlar a atividade amilolítica após o quarto dia de germinação, bem como, até a própria concentração de amido existente no malte, a qual modifica a cinética da reação (BIAZUS et al., 2006a, 2006b; HALPERN, 1997; RICARDO; TEIXEIRA, 1993; CURVELO-SANTANA, 2003).

Os resultados obtidos neste trabalho foram superiores aos obtidos por Curvelo-Santana (2003) e por Ferreira et al. (2007), que purificaram as amilases de malte de milho com sistema bifásico aquoso $\mathrm{PEG} / \mathrm{CaCl}_{2}$; por Biazus et al. (2007) e por Severo Jr. et al. (2007), que purificaram as amilases de malte de milho usando extração líquido-líquido e processos de separação por membranas, respectivamente. O Fator de purificação na condição ótima da precipitação também foi superior aos obtidos por Aguilar et al. (2000), que purificaram amilases de Lactobacillus manihotivorans por cromatografia em gel; que Blasquez et al. (1998) e Furuya et al. (1995, 1996), que purificaram amilases de $A$. níger por sistemas bifásicos aquosos PEG/ $\mathrm{MgSO}_{4}$ e PEG/fosfato, respectivamente; que Nirmala e Muralikrishna (2003), que purificaram amilases de malte de milheto por cromatografia em gel; e que Toledo et al. (2007), que purificaram amilases de A. níger por adsorção em leito expandido. Seu valor foi semelhante ao obtido por Mendu et al. (2005), que purificaram amilases de Bacillus lincheniformis usando cromatografia de alta resolução.

A Figura 5 apresenta a análise via eletroforese por SDSPAGE com as amostras do malte de milho bruto e purificada por ALE combinada com a precipitação com álcool na condição de fracionamento a $50-80 \%$ a $20{ }^{\circ} \mathrm{C}$, após passarem por microfiltração com membrana de $10 \mu \mathrm{m}$ de diâmetro de poros, para eliminação da interferência salina. Nesta eletroforese, o malte apresenta várias bandas em toda a extensão do gel, indicando que sua composição apresenta diversas proteínas. Já para a amostra precipitada, nota-se que apenas duas bandas são apresentadas mostrando que o processo foi efetivo na purificação do material, já que este apresenta atividade enzimática e contém só duas proteínas com massas molares de 69,4 e 45,6 kDa, respectivamente.

De acordo com Aguilar et al. (2000), Mendu et al. (2005), Nirmala e Muralikrishna (2003), Reguly (1996), Curvelo-Santana (2003) e Wiseman (1987), estas podem ser as enzimas desejadas, pois suas massas molares estão entre 50$120 \mathrm{kDa}$ para a $\alpha$-amilase $(69,4 \mathrm{kDa})$ e entre $20-50 \mathrm{kDa}$ para a

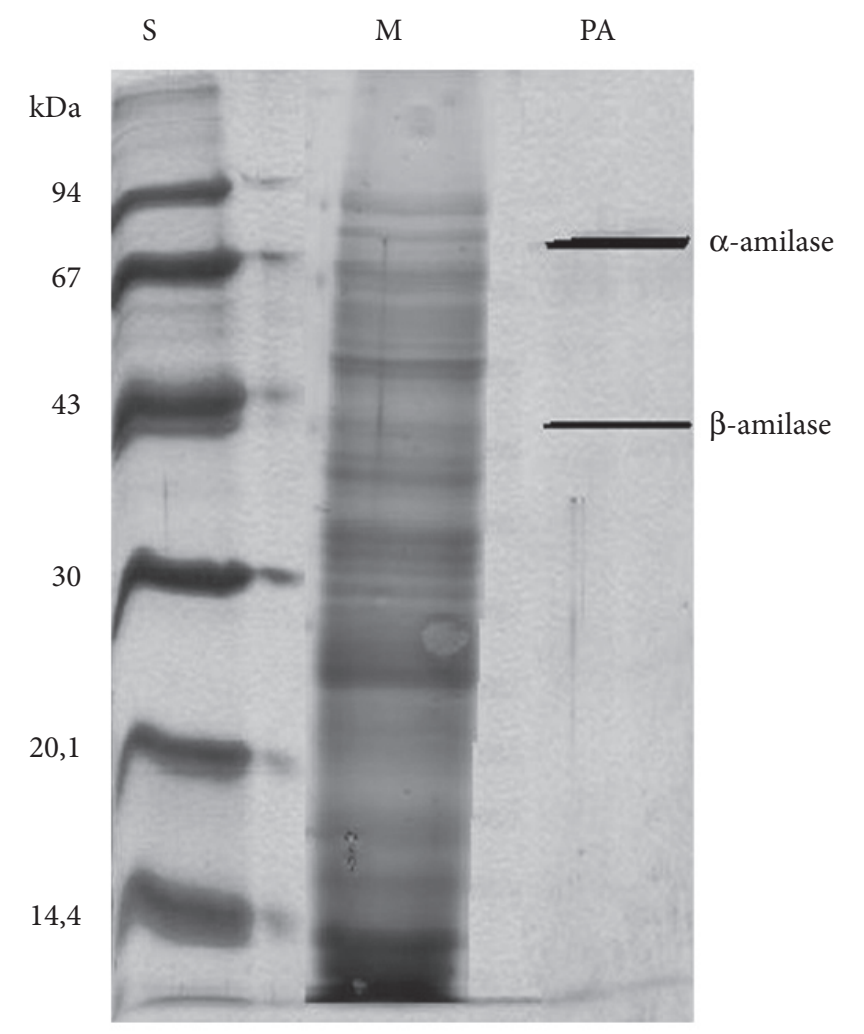

Figura 5. Determinação da massa molar das proteínas nas amostras por eletroforese via SDS-PAGE. Onde S é o padrão de massa molar, composto das seguintes proteínas: fosforilase b (94 kDa), albumina de soro bovino $(67 \mathrm{kDa}$, albumina de ovo $(43 \mathrm{kDa})$, carbonidase $(30 \mathrm{kDa})$, inibidor de tripsina $(20,1 \mathrm{kDa})$ e $\alpha$-lacto albumina $(14,4 \mathrm{kDa})$. M é a amostra de malte bruta e A é a amostra purificada por ALE e posterior precipitação fracionada de 50-80\% com álcool.

$\beta$-amilase $(45,6 \mathrm{kDa})$. Resultados semelhantes foram obtidos por Biazus et al. (2007), que purificaram as a e $\beta$-amilases de malte de milho em uma coluna de extração líquido-líquido, usando os sistemas bifásicos aquosos $\mathrm{PEG} / \mathrm{CaCl}_{2}$.

\section{Conclusões}

A purificação por adsorção em leito expandido usando as resinas de troca aniônica Amberlite IRA 410 mostrou-se muito 
efetiva, conseguindo recuperar mais de $96 \%$ da atividade inicial do malte e chegando a um fator de purificação de 23 vezes, o que indica uma boa afinidade desta resina com as enzimas amilolíticas do malte de milho.

O maior fator de purificação foi de 100 vezes, obtido durante a etapa de precipitação, quando se usou um fracionamento de $50 \%$ para $80 \%$ de álcool, a $20^{\circ} \mathrm{C}$.

Como o álcool etílico e a resina possuem preços baixos (quando comparados com preços de outras resinas cromatográficas, apresentados no catálogo da SIGMA, 1996), pode-se concluir que este trabalho mostrou que as amilases de malte de milho podem ser obtidas com bom grau de pureza, bom potencial enzimático e a baixo custo de produção. Assim, é possível agregar valor à cultura do milho pela produção destas enzimas em escala industrial.

\section{Agradecimentos}

Os autores agradecem ao $\mathrm{CNPq}$ (Brasília - DF), à FAPESP (São Paulo - SP) e ao PIBIC/ CNPq-UFS (São Cristóvão - SE) os auxílios financeiros.

\section{Referências bibliográficas}

ALMEIDA, M. S.; KURTENBACH, E. Como purificar proteínas. Revista BIO ICB. Disponível em: < http://www.icb.ufrj.br >. Acesso em: jul. 2002.

AGUILAR, G. et al. Purification and characterization of an extracellular a-amylase produced by Lactobacillus manihotivorans LMG $18010^{\mathrm{T}}$, an amylolytic lactic acid bacterium. Enzyme and Microbial Technology, v. 27, n. 6, p. 406-413, 2000.

BIAZUS, J. P. M. et al. Continuous extraction of $\alpha$ - and $\beta$-amylases from Zea mays malt in a PEG4000/CaCl2 ATPS. Journal of Chromatography B, v. 858, n. 1, p. 227-233, 2007.

BIAZUS, J. P. M. et al. Study of amylases recovery from maize malt by ion-exchange expanded bed chromatography. Process Biochemistry, v. 41, n. 8, p. 1786-1791, 2006a.

BIAZUS, J. P. M. et al. Otimização da secagem do malte de Zea mays. Ciência e Tecnologia de Alimentos, v. 26, n. 4, p. 787-792, $2006 \mathrm{~b}$.

BIAZUS, J. P. M. et al. Caracterização da atividade amilásica do malte de milho (Zea mays). Acta Scientiarum, v. 28, n. 1, p. 13-19, $2006 \mathrm{c}$.

BIAZUS, J. P. M. et al. Optimization of drying process of Zea Mays malt to use as alternative source of amylolytics enzymes. Brazilian Archives of Biology and Technology, v. 48, n. special, p. 185-190, 2005a.

BIAZUS, J. P. M. et al. Maximizing of production stages of malt from Zea mays. Brazilian Journal of Food Technology, v. special, p.138$145,2005 \mathrm{~b}$.

BLÁSQUEZ, G. et al. Partition coefficients of $\alpha$-amylase in aqueous two-phase systems $\mathrm{PEG}+\mathrm{MgSO}_{4} \cdot 7 \mathrm{H}_{2} \mathrm{O}$ at $298 \mathrm{~K}$. Biochimica et Biophysica Acta, v. 1379, n. 3, p.191-197, 1998.

BRADFORD, M. M. A rapid and sensitive method for the quantization of microgram quantities of protein: utilizing the principlee of protein-dye binding. Analytical Biochemistry, v. 72, n. 1, p. 248254, 1976.

CARVALHO, A. V.; GARCIA, N. H. P.; WADA, J. K. A. Caracterização físico-química e curvas de solubilidade protéica de sementes "in natura": amêndoas fermentadas e torradas de cupuaçu (Theobroma grandiflorum Schum). In: CONGRESSO BRASILEIRO DE FRUTICUlTURA, 17, 2005, Pelotas. Anais... Disponível em:
$<$ http://www.ufpel.tche.br/sbfruti/anais_xvii_cbf/ tecnologia_de_ alimentos/ 791.htm>. Acesso em: ago. 2005.

CURVELO-SANTANA, J. C. Recuperação das enzimas $\alpha$ e $\beta$ amilases em sistema bifásico aquoso PEG/CACL2 para uso como biocatalizador de amiláceos. Campinas, 2003. 232 p. Dissertação (Mestrado) - Universidade Estadual de Campinas - UNICAMP.

DAINIAK, M. B.; GALAEV, I. Y.; MATIASSON, B. Directed capture of product from fermentation broth using a cell-repelling ion exchanger. Journal of Chromatography A, v. 942, n. 1, p. 123-131, 2002.

FERREIRA, G. B. et al. Partitioning optimization of proteins from Zea mays malt in ATPS PEG $6000 / \mathrm{CaCl}_{2}$. Brazilian Archives of Biology and Technology, v. 50, n. 3, p. 557-564, 2007.

FURUYA, T. et al. Measurement and correlation of partition coefficients of hydrolytic enzymes for dextran + poly(ethylene glycol) + water aqueous two-phase systems at $20^{\circ} \mathrm{C}$. Fluid phase Equilibria, v. 110, n. 1, p. 115-128, 1995.

FURUYA, T. et al. Measurement and correlation of liquid-liquid equilibria and partition coefficients of hydrolytic enzymes for DEX $\mathrm{T} 500$ + PEG20000 + water aqueous two-phase systems at $20^{\circ} \mathrm{C}$. Fluid phase Equilibria, v. 125, n. 1, p. 89-102, 1996.

HALPERN, M. J. Bioquímica. 1 ed. Lisboa: Lidel, 1997.

KALIL, S. J. Produção de inulinase por Kluyveromyces marxianus e purificação da enzima por cromatografia de troca iônica em coluna de leito expandido. Campinas, 2000. 132 p. Tese (Doutorado) - Universidade Estadual de Campinas - UNICAMP.

LAEMMLI, U. K. Cleavage of structural proteins during the assembly of head of Bacteriophage T4. Nature, v. 227, n. 5259, p. 680-685, 1970.

LUCCARINI, A. C.; KILIKIAN, B. V.; PESSOA Jr., A. Precipitação. In: PESSOA Jr., A.; KILIKIAN, B. V. (coords.). Purificação de produtos biotecnológicos. Barueri: Manole, 2005. p. 89-113. (v. 1)

MENDU, D. R. et al. Affinity chromatography of a-amylase from Bacillus lincheniformis. Enzyme and Microbial Technology, v. 31, n. 7, p.712-717, 2005.

NIRMALA, M.; MURALIKRISHNA, G. Three $\alpha$-amylase from malted finger millet (Ragi, Eleusine coracana, Indaf-15): purification and partial characterization. Phytochemistry, v. 62, n. 1, p. 21-23, 2003.

REGULY, J. C. Biotecnologia dos processos fermentativos. Pelotas: EDUFPel, 1996. 330 p. (v. 1)

RICARDO, C. P.; TEIXEIRA, A. Enzimas. 4 ed. Lisboa: Plátano Editora S.A., 1993.98 p.

ROY, I. et al. Comparison of batch, packed bed and expanded bed purification of $A$. niger cellulase using cellulose beads. Bioseparation, v. 8, n. 6, p. 317-326, 1999.

SANTOS, E. S. Recuperação e purificação de enzimas usando adsorção em leito expandido. Campinas, 2001, 152 p. Tese (Doutorado) - Universidade Estadual de Campinas - UNICAMP.

SEVERO Jr., J. B. et al. Response surface methodology to evaluation the recovery of amylases by hollow fiber membrane. Brazilian Archives of Biology and Technology, v. 50, n. 4, p. 713-718, 2007.

SIGMA CHEMICAL COMPANY. Biochemicals organic compounds and diagnostic reagents. St. Louis, 1996. p. 116-117.

STREETER, V. L. Mecânica dos fluidos. São Paulo: Mcgraw Hill, 1977. $736 \mathrm{p}$

TOLEDO, A. L. et al. Purification by expanded bed adsorption and characterization of an $\alpha$-amylases FORILASE NTL ${ }^{\oplus}$ from $A$. niger. Journal of Chromatography B, v. 846, n. 1, p. 51-56, 2007.

WISEMAN, A. Handbook of enzyme biotechnology. 2 ed. New York: John Wiley Sons, 1987. 